\title{
Hydrogen refueling station cost model applied to five real case studies for fuel cell buses
}

\author{
Roberta Caponi ${ }^{1, *}$, Andrea Monforti Ferrario ${ }^{2}$, Luca Del Zotto ${ }^{3}$, and Enrico Bocci ${ }^{1}$ \\ ${ }^{1}$ Department of Engineering Science, Guglielmo Marconi University, 00193 Rome, Italy \\ ${ }^{2}$ ENEA, Italian National Agency for New Technologies, Energy and Sustainable Economic \\ Development, TERIN-PSU-ABI, 00123 Rome, Italy \\ ${ }^{3}$ CREAT, Centro di Ricerca su Energia, Ambiente e Territorio, Università Telematica eCampus, \\ 22060 Novedrate, Italy
}

\begin{abstract}
Hydrogen Refueling Stations (HRS) are a key infrastructure to the successful deployment of hydrogen mobility. Their cost-effectiveness will represent an increasingly crucial issue considering the foreseen growth of vehicle fleets, from few captive fleets to large-scale penetration of hydrogen vehicles. In this context a detailed, component-oriented cost model is important to assess HRS costs for different design concepts, layout schemes and possible customizations, respect to aggregate tools which are mostly available in literature. In this work an improved version of a previously developed component-oriented, scale-sensitive HRS cost model is applied to 5 different European HRS developed within the 3Emotion project with different refueling capacities $\left(\mathrm{kg}_{\mathrm{H}} / \mathrm{day}\right)$, hydrogen supply schemes (in-situ production or delivery), storage volumes and pressures and operational strategies. The model output allows to assess the upfront investment cost (CAPEX), the annual operational cost (OPEX) and the Levelized Cost of Hydrogen ( $\mathrm{LCOH}$ ) at the dispenser and identify the most crucial cost components. The results for the five analyzed HRS sites show an $\mathrm{LCOH}$ at the nozzle of around $8-9 € / \mathrm{kg}$ for delivery based HRSs, which are mainly dominated by the $\mathrm{H}_{2}$ retail price and transport service price and around $11-12 € / \mathrm{kg}$ for on-site producing HRS, for which the electrolyzer CAPEX and electricity price plays a key role in the cost structure. The compression, storage, and dispensing sections account for between $1-3 € / \mathrm{kg}$ according to the specific design \& performance requirements of the HRS. The total LCOH values are comparable with literature, standard market prices for similar scale HRSs and with the 3Emotion project targets.
\end{abstract}

\section{Introduction}

Hydrogen fuelling stations (HRSs) are one of the most critical parts of the distribution infrastructure required to implement hydrogen-powered mobility. Without a widespread hydrogen refuelling network, hydrogen vehicles are strongly limited in terms of operation and their commercial deployment will be very limited. At the same time, without a significant fleet of operational hydrogen fuel cell vehicles, building a viable business case for setting up a network of HRSs is challenging due to the lack of consistency in hydrogen demand ${ }^{1,2}$. The so-called chicken-and-egg problem determines a lack of spontaneous growth in hydrogen mobility sector in European market, which is mainly driven by public or private project-

*Corresponding author: r.caponi@lab.unimarconi.it 
specific funding ${ }^{3}$. This situation could rapidly change with the mass deployment of hydrogen mobility projects both in terms of hydrogen-powered vehicles and refuelling infrastructure, with about 3700 refuelling stations announced and planned in Europe by $2030^{4}$. The deployment of HRSs throughout European cities is crucial to provide a valid commercial benchmark for the hydrogen stations in terms of used technology (production and distribution), technical specifications, layout, and economics ${ }^{5}$.

The most mature and industrially common HRSs categories are the ones with delivered hydrogen (by compressed hydrogen via truck/pipeline or liquid hydrogen) or with production units on-site. Depending on the site specific requirements and constraints, one or the other solution is preferable. Delivery stations are simple and compact, consequently, the station investment cost (CAPEX) is moderate ${ }^{6}$. However, the hydrogen cost will strictly depend on the hydrogen retail price and utility costs and is not controllable by the final user (although constant with operating conditions at contract price) ${ }^{7}$. The fuel price must take into account also delivery and vehicle leasing fees which are usually in the same order as the retail hydrogen price ${ }^{8}$. An increased complexity characterizes on-site HRSs since the hydrogen production plant is integrated with the filling station and coupled with compression units. Therefore, if from an operational point of view is more versatile, directly controlling the flow rate, the CAPEX costs are generally higher and the footprint more extended ${ }^{9}$. On the contrary, the operational cost (OPEX) can decrease significantly in the case of low electricity price schemes or on-site electricity production from renewable energy sources ${ }^{10}$.

According to the cost modelling approach, various levels of detail and aggregation in cost models can be achieved which can lead to substantial differences in the results. On the one hand a highly aggregated system-oriented approach estimating the HRS cost and the Levelized Cost of Hydrogen $(\mathrm{LCOH})$ as a function of the HRS capacity $(€ /(\mathrm{kg} /$ day $))$ can be useful for early-stage project development or quick prototyping of integrated hydrogen ecosystems ${ }^{11-13}$; on the other hand a more detailed component-oriented analyses which builds up the HRS cost and LCOH as an assembly of unit costs is more realistic but is usually more suitable for advanced stages of project implementation and engineering ${ }^{14-17}$, being somewhat cumbersome to apply in early project stages due to lack of specific data. A tradeoff must be found between these two approaches according to function of the objective and level of detail required by the analysis, obtaining a reliable cost output with sufficient degree of detail in the cost breakdown but at the same time maintaining a simple and versatile cost model, which can be easily applicable to different case studies.

The aim of this study was to tailor a previously developed component-oriented cost model $^{18}$ to evaluate in detail the CAPEX, the OPEX, and the LCOH for five European HRSs for fuel cell buses developed within the 3Emotion project ${ }^{19}$ characterized by different refuelling capacities $\left(\mathrm{kg}_{\mathrm{H} 2} /\right.$ day), hydrogen supply schemes (in-situ production or delivery), storage volumes and pressures and operational strategies. The ultimate goal of the work is to put the analysis of the sites into a clear industrial context and to be able to assess the 3Emotion sites in comparison to state-of-art references and industrial practice ${ }^{14,20-22}$.

\section{Case study: the 3Emotion project}

In Table 1 the main characteristics of the five Hydrogen Refuelling Stations of the 3Emotion project are summarized. Since two different bus operators are present in the Rhoon and Versailles sites, two different business cases have been analyzed for each of the operators. 
Table 1. Summary of the 3Emotion HRSs and main parameters.

\begin{tabular}{|c|c|c|c|c|c|c|c|c|c|}
\hline \multirow[t]{2}{*}{ Site } & \multirow{2}{*}{\multicolumn{2}{|c|}{ Hydrogen source }} & $\begin{array}{l}\text { Nominal } \\
\text { Capacity }\end{array}$ & $\begin{array}{l}\text { Supply } \\
\text { scheme }\end{array}$ & $\begin{array}{c}\text { Compressor } \\
\text { pressures }\end{array}$ & $\begin{array}{c}\text { Compressor } \\
\text { max. throughput }\end{array}$ & $\begin{array}{l}\text { Storage } \\
\text { capacity }\end{array}$ & $\begin{array}{c}\text { Storage } \\
\text { pressure* }\end{array}$ & $\begin{array}{c}\text { Dispenser } \\
\text { pressure }\end{array}$ \\
\hline & & & $\mathrm{kg} / \mathrm{day}$ & onsite/delivery & $\mathbf{b a r}_{\text {in }} / \mathbf{b a r}_{\text {out }}$ & $\mathrm{Nm}^{3} / \mathrm{h}$ & kg & kg@bar & bar \\
\hline London & $\begin{array}{l}\text { Delivery } \\
\text { trailer } * *\end{array}$ & $\begin{array}{c}450 \mathrm{~kg} / \text { trailer } \\
\text { @ } 350 \mathrm{bar}\end{array}$ & $\begin{array}{l}400 \mathrm{~kg} / \text { day } \\
\approx 300 \mathrm{~km}\end{array}$ & $2 \mathrm{del} . /$ week & $350 / 500$ & $\begin{array}{l}\text { Integrated in } \\
\text { trailer }\end{array}$ & $1250 \mathrm{~kg}$ & $\begin{array}{c}900 \mathrm{~kg} @ 350 \mathrm{bar} \\
\text { trailer } \\
350 \mathrm{~kg} @ 500 \mathrm{bar} \\
\text { onsite }\end{array}$ & $1 \times 350$ bar \\
\hline $\begin{array}{l}\text { Rhoon } \\
\text { RET }\end{array}$ & \multirow{2}{*}{$\begin{array}{l}\text { Delivery } \\
\text { pipeline }\end{array}$} & \multirow{2}{*}{$\begin{array}{c}\text { (a) } 30 \text { bar from } \\
\text { SMR plant }\end{array}$} & \multirow{2}{*}{$\begin{array}{l}200 \mathrm{~kg} / \text { day } \\
\approx 100 \mathrm{~km}\end{array}$} & \multirow{2}{*}{$\begin{array}{c}\text { Upon } \\
\text { request }\end{array}$} & \multirow{2}{*}{$\begin{array}{c}2 \times 30 / 495 \\
1 \times 350 / 900\end{array}$} & \multirow{2}{*}{$100 \mathrm{Nm}^{3} / \mathrm{h}$} & \multirow{2}{*}{$250 \mathrm{~kg}$} & $\begin{array}{l}90 \mathrm{~kg} @ 495 \mathrm{bar} \\
65 \mathrm{~kg} @ 877 \mathrm{bar}\end{array}$ & $1 \times 350$ bar \\
\hline $\begin{array}{c}\text { Rhoon } \\
\text { PZH }\end{array}$ & & & & & & & & 95 kg@495 bar & $1 \times 350$ bar \\
\hline $\begin{array}{l}\text { Versailles } \\
\text { SAVAC }\end{array}$ & \multirow{2}{*}{$\begin{array}{l}\text { Delivery } \\
\text { trailer } * *\end{array}$} & \multirow{2}{*}{$\begin{array}{l}350 \mathrm{~kg} / \text { trailer } \\
\text { (a) } 200 \mathrm{bar}\end{array}$} & \multirow{2}{*}{$\begin{array}{l}200 \mathrm{~kg} / \text { day } \\
\approx 200 \mathrm{~km}\end{array}$} & \multirow{2}{*}{$3 \mathrm{del} . /$ week } & \multirow{2}{*}{$\begin{array}{l}1 \times 10 / 1080 \\
(2 \text {-stage })\end{array}$} & \multirow{2}{*}{$150 \mathrm{Nm}^{3} / \mathrm{h}$} & \multirow{2}{*}{$600 \mathrm{~kg}$} & \multirow{2}{*}{$\begin{array}{c}350 \mathrm{~kg} @ 200 \mathrm{bar} \\
\text { trailer } \\
100 \mathrm{~kg} @ 495 \mathrm{bar} \\
\text { onsite } \\
60 \mathrm{~kg} @ 877 \mathrm{bar}\end{array}$} & $350 / 700$ bar \\
\hline $\begin{array}{l}\text { Versailles } \\
\text { BE Green }\end{array}$ & & & & & & & & & $\begin{array}{c}1 \times 350 / 700 \\
\text { bar } \\
1 \times 350 \text { bar }\end{array}$ \\
\hline $\begin{array}{c}\text { Pau } \\
\text { SMTU }\end{array}$ & $\begin{array}{c}\text { On-site } \\
\text { electrolysis } \\
+ \text { delivery } \\
\text { trailer }\end{array}$ & $\begin{array}{l}\text { PEMEL: } 425 \mathrm{~kW} \\
\text { Trailer: } 330 \mathrm{~kg} \\
\text { @ } 200 \mathrm{bar}\end{array}$ & $\begin{array}{c}174 \\
\mathrm{~kg} / \text { day }^{* * *}\end{array}$ & $24 / 24 h$ & $\begin{array}{c}2 \times 7-20 / 920 \\
(5 \text {-stage })\end{array}$ & $2 \times 275 \mathrm{Nm}^{3} / \mathrm{h}$ & $860 \mathrm{~kg}$ & $\begin{array}{c}230 \mathrm{~kg} @ 20 \mathrm{bar} \\
630 \mathrm{~kg} @ 600 \mathrm{bar} \\
(330 \mathrm{~kg} @ 200 \mathrm{bar} \\
\text { trailer optional) }\end{array}$ & $8 \times 350$ bar \\
\hline Aalborg & $\begin{array}{c}\text { On-site } \\
\text { electrolysis }\end{array}$ & PEMEL: $355 \mathrm{~kW}$ & $100 \mathrm{~kg} /$ day & $\begin{array}{c}\approx 80 \% \\
\text { capacity } \\
\text { factor }\end{array}$ & $\begin{array}{l}1 \times 35 / 450 \\
\text { (3-stage) }\end{array}$ & $60 \mathrm{Nm}^{3} / \mathrm{h}$ & $242 \mathrm{~kg}$ & $\begin{array}{c}10 \mathrm{~kg} @ 30 \mathrm{bar} \\
114 \mathrm{~kg} @ 300 \mathrm{bar} \\
118 \mathrm{~kg} @ 450 \mathrm{bar}\end{array}$ & 1x 350 bar \\
\hline
\end{tabular}

* Specifying different pressure levels

*** Blue Hydrogen

**** Max. capacity $268 \mathrm{~kg} / \mathrm{day}$ 


\subsection{London site}

The HRS in London is located in the Temple mills depot and consists of an $\mathrm{H}_{2}$ delivery station with a fuelling capacity of $400 \mathrm{~kg} /$ day against a request of $160 \mathrm{~kg} /$ day due to a fleet of 10 buses. Hydrogen is delivered by $\mathrm{LH}_{2}$ trailer transporting blue hydrogen produced by SMR in the SMR plant of Rotterdam and transported for $300 \mathrm{~km}$ up to the HRS. The $\mathrm{LH}_{2}$ trailer is an integrated system (not considered within the model) which includes a cryogenic tank for the $\mathrm{LH}_{2}$, a vaporization unit to convert the $\mathrm{LH}_{2}$ to gaseous form and an integrated compression unit for discharge of the hydrogen capacity $(450 \mathrm{~kg})$ up to 350 bar into the on-site storage units. The hydrogen trailer which is delivered to the HRS twice a week is later used as integrated storage, with a capacity up to $900 \mathrm{~kg}$ at $350 \mathrm{bar}$, in addition to the $350 \mathrm{~kg}$ onground permanent storage at $500 \mathrm{bar}$, for a total capacity of $1250 \mathrm{~kg}$. Hydrogen is transferred from the trailers to the on-site storage with a hydrogen compression system directly integrated in the trailer unit, therefore no specific station equipment is needed from the HRS to discharge the supplied hydrogen. The filling system is based on a single dispenser that allows to refill the entire fleet of 10 buses in 4 hours, a procedure usually carried out during the night.

\subsection{Rhoon/Rotterdam site}

Rhoon is a publicly accessible HRS nearby Rotterdam supplying hydrogen to both hydrogenpowered cars and buses. Refueling occurs for buses at a pressure of 350 bar, while for cars with a dual pressure of 700 bar and 350 bar. The Rhoon HRS is supplied from the Benelux/France pipeline of $900 \mathrm{~km}$ overall (specifically in the section between Rotterdam and Antwerp - $\approx 100 \mathrm{~km}$ ) with a pressure level of 70-100 bar which can be compressed and stored on-site at various pressures. Originally it is produced by SMR and by chloralkali process starting from LNG from a tanker in Antwerp. The hydrogen is delivered continuously at the point of connection with the Rhoon HRS at 30 bar, where it is directly fed to the first stage of compression (30/495 bar) and then to a high pressure (350/900 bar) compressor in series. The storage is composed of a medium pressure (90 kg@495 bar) and a high pressure (65 kg@877 bar) compressed gas storage unit for a total stored capacity of $155 \mathrm{~kg}$. An additional medium pressure compressor (30/495 bar) has been added to upgrade the HRS with the additional buses. The station has installed 3 dispensers, one fast-filling for 700 bar with pre-cooling heat exchanger with closed-loop refrigerant circuit, one for 350 bar for cars and lastly one for 350 bar for buses (which is the one used in the 3Emotion project) without pre-cooling. In relation to the increase of the buses fleet the Rhoon HRS has been upgraded, implementing an additional medium pressure compressor (30/495 bar); an additional medium pressure buffer ( $95 \mathrm{~kg} @ 495 \mathrm{bar}$ ) to achieve a total storage capacity of about $250 \mathrm{~kg}$ of useful storage and an additional dedicated 350 bar dispenser.

\subsection{Versailles site}

The Versailles HRS is used to refuel a fleet of 7 buses at 350 bar with a rated capacity of around $200 \mathrm{~kg}$ /day operated by two transport operators (with 2 buses and 5 buses), and about 40 light vehicles using separate dual pressure dispensers (350/700 bar). Hydrogen is delivered by tube trailer with 2-3 deliveries/week from a reforming plant with carbon capture (blue hydrogen), with trailers of $350 \mathrm{~kg}$ of $\mathrm{H}_{2}$ at a pressure of 200 bar which are left in the HRS as storage unit. The trailers from Versailles deliver blue hydrogen produced in the SMR plants of Frais Marais $(250 \mathrm{~km})$ and Port Jérôme $(150 \mathrm{~km})$. The compression system is divided into two stages, the first allows to reach 450 bar, while the second can reach up to 1080 bar (although it is operated at lower discharge pressures). In addition to the tube trailers 
delivered 2-3 times/week that can contain $350 \mathrm{~kg}$ of $\mathrm{H}_{2}$, the Versailles HRS can count on an intermediate storage of about $100 \mathrm{~kg}$ of $\mathrm{H}_{2}$ at a pressure of 495 bar and a high pressure storage of $60 \mathrm{~kg}$ of $\mathrm{H}_{2}$ at a pressure of around 880 bar allowing to have on the site a total availability of $510 \mathrm{~kg}$ of $\mathrm{H}_{2}$ compared to a daily demand of around $200 \mathrm{~kg}$. The initial dual flow dispenser (350 bar and 700 bar) with separated nozzle, has been upgraded with an additional dispenser dedicated to the fuel cell buses (350 bar).

\subsection{Pau site}

The HRS of Pau is a station with local hydrogen production by a PEM electrolyzer ( $425 \mathrm{~kW})$ which can provide around $174 \mathrm{~kg} /$ day of hydrogen at nominal capacity to supply 8 buses; the daily production capacity is incrementable to $268 \mathrm{~kg}$ /day. A backup hydrogen supply via tube trailers (330 kg@200 bar) can be used for backup. Since the tube trailers in Pau are only used for backup, the production plant is not fixed. The produced hydrogen is directly stored at the electrolyzer output pressure in a low-pressure storage unit (230 kg @20 bar) which is subsequently connected to two parallel ionic compressors (20/920 bar) to compress the gas up to the high-pressure storage units (630 kg @600 bar) for a total available capacity of 860 $\mathrm{kg}$, other than the possible presence of the backup trailer (330 kg@200 bar trailer - optional). The dispensing system is designed to provide one refuelling point for each bus, therefore 8 separate dispensing points are available.

\subsection{Aalborg site}

The HRS in Aalborg produces $\mathrm{H}_{2}$ directly on-site with a rated capacity of about $100 \mathrm{~kg} / \mathrm{day}$. The total production capacity $-100 \mathrm{~kg} /$ day nominal - is obtained by a locally producing pressurized PEM electrolyzer ( $355 \mathrm{~kW}$ with an output pressure of $35 \mathrm{bar}$ ). The hydrogen is directly stored in a low-pressure buffer storage at 35 bar (10 kg@35 bar), then compressed by a single-piston type compressor (35/450 bar) to 300 bar and 450 bar, according to the storage unit used (114 kg@300 bar and 118 kg@450 bar). From the storages hydrogen is refuelled to the buses at 350 bar with a single dispenser

The Hydrogen Refueling Stations of the 3Emotion project are summarized in Figure 1 in terms of refueling capacity.

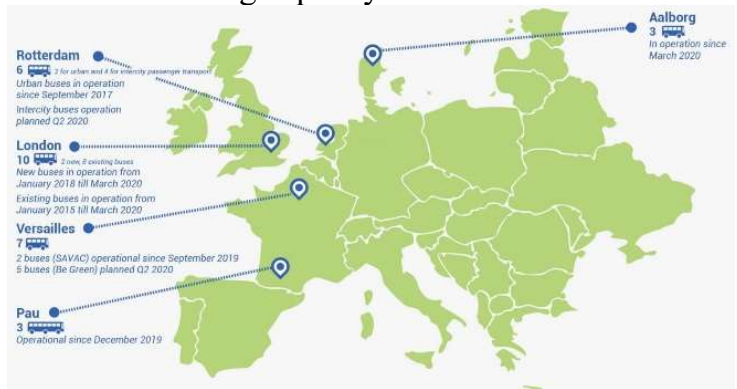

(a)

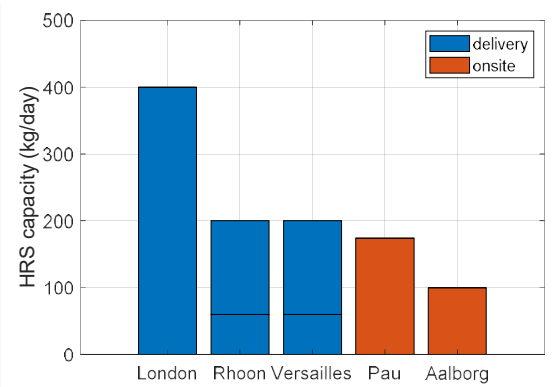

(b)

Fig. 1. (a) Summary of Hydrogen Refueling Stations in the 3Emotion project; (b) refueling capacity

\section{Hydrogen Refuelling Station Cost Model}

The implemented HRS cost model follows a component-oriented approach based on the design specification parameters. Each component is assessed in terms of CAPEX (investment cost, replacements, etc.) and yearly OPEX (energy cost, utility cost, O\&M, etc.) according to the integration scheme in the overall HRS plant. 
The battery limit of the cost model is limited to the local HRS boundary (hydrogen production, compression, storage and dispensing units) while grid electricity and delivered $\mathrm{H}_{2}$ are seen as external inputs, providing material and energy inputs $\left(\mathrm{kg}_{\mathrm{H} 2}\right.$ and $\mathrm{kWh}_{\mathrm{e}}$, respectively) according to the operating scheme of the HRS. In this way, the upstream electricity and $\mathrm{H}_{2}$ production methods are not assessed in the cost model, as they are included in their retail prices $\left(€ / \mathrm{kg}_{\mathrm{H} 2}\right.$ and $€ / \mathrm{kWh}_{\mathrm{e}}$, respectively), as seen by the HRS operator. The cost model output is calculated at the dispenser nozzle from the HRS to the fuel cell buses at 350 bar, where the vehicle cost and consumption are not included within the scope of the HRS cost model.

A conceptual scheme of the HRS cost model is illustrated in Figure 2.

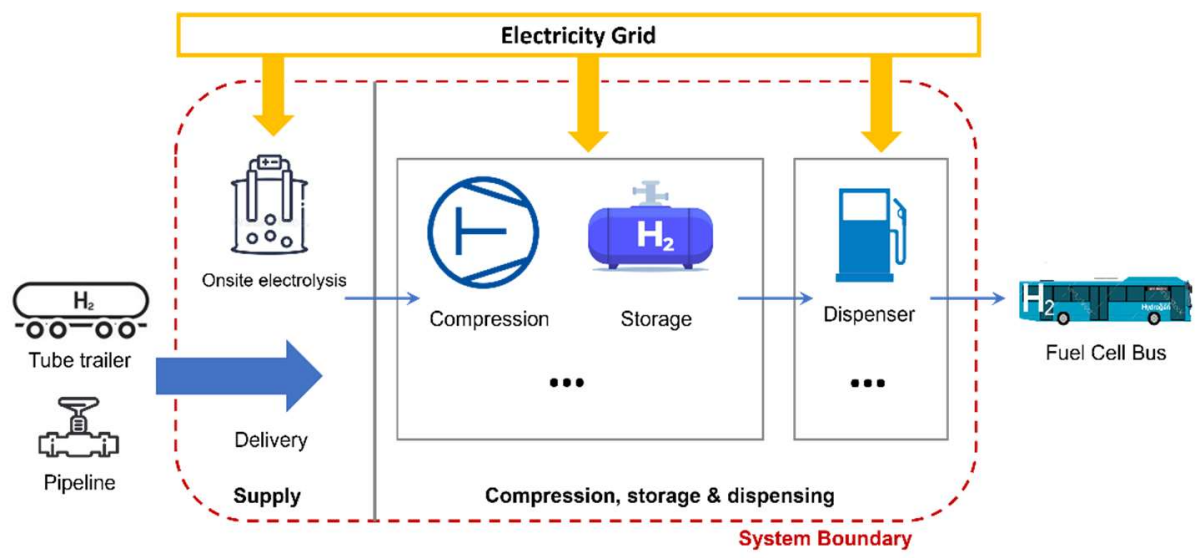

Fig. 2. Conceptual scheme of the Hydrogen Refueling Station cost model

\subsection{On-site hydrogen production - electrolysis}

In the on-site producing HRSs the $\mathrm{H}_{2}$ is produced by electrolysis, which is an electrochemical conversion system which decomposes water in its constituents $\mathrm{H}_{2}$ and $\mathrm{O}_{2}$ via the application of a current across an electrochemical membrane electrode assembly. The electrolyzer technology determines the operating conditions at stack level (current density and required voltage levels) and system level (considering the requirements in terms of balance of plant), ultimately determining the specific energy consumption (SEC) at system level $\left(\mathrm{kWh}_{\mathrm{e}} / \mathrm{kg}_{\mathrm{H} 2}\right)$ and the electrical-to-hydrogen efficiency $(\%)^{10,23}$.

Both on-site producing HRSs (Pau and Aalborg) implement PEM electrolysis technology therefore only this technology is analyzed in the cost model. In both the HRSs the electrolyzer is supplied from the grid (grid-connected mode).

The summary of the PEM electrolyzer technology technical parameters are reported in Table 2. Although presenting a SEC of around $6-6.5 \mathrm{kWh}_{\mathrm{e}} / \mathrm{Nm}^{3}$ (i.e., an electrical to hydrogen efficiency around $55-65 \%$ based on HHV) which is slightly higher compared to the competing low temperature technology which is alkaline electrolysis $-5-5.5 \mathrm{kWh} / \mathrm{Nm}^{3}$, i.e. $70-75 \%$ efficiency based on HHV - PEM systems are more suitable for coupling with variable electrical supply profiles with high intermittency and are suitable for power modulation $^{24}$. For this reason, PEM electrolysis is a particularly promising technology for application in HRSs, since the operating scheme is characterized by a strongly intermittent and on-off operation profile, in relation to the discrete nature of the hydrogen load (vehicle refueling). From a balance of plant point of view the PEM technology presents fairly simple operation due to the polymeric electrolyte in solid phase, which avoids any pumps or moving parts related to electrolyte management. On the other hand, higher power density values can result in higher cooling loads, although overall the additional auxiliary energy demand of 
PEM electrolysis is around $5 \%$ of the SEC at stack level respect to $10 \%$ for alkaline systems ${ }^{25}$. The stoichiometric water consumption is around $1 \mathrm{lt} / \mathrm{Nm}^{3}$ of demineralized water, where the water treatment system energy consumption is included in the additional auxiliary energy consumption (with potable water input, in case of seawater input the desalination energy consumption should be added), as well as the hydrogen purification system located downstream the electrolyzer (dryer, de-Ox, etc.) required for utilization in FCEV applications (class 5.0 purity according to SAE $\mathrm{J} 2719^{26}$ ).

Table 2. Summary of technical and economic parameters for PEM electrolysis ${ }^{24}$.

\begin{tabular}{|l|l|l|l|}
\hline \multicolumn{2}{|l|}{ Technical Parameters } & \multicolumn{2}{l|}{ Cost Parameters } \\
\hline SEC (stack level) & $6.2 \mathrm{kWh} / \mathrm{Nm}^{3}$ & $\begin{array}{l}\text { CAPEX (system }+ \\
\text { BoP) }\end{array}$ & $\begin{array}{l}\text { Eq. 1 } \\
\text { Base-case } 100 \mathrm{~kW}_{\mathrm{e}} ; \\
2000 € / \mathrm{kW}_{\mathrm{e}} ; \\
\text { s.f. } 0.45\end{array}$ \\
\hline $\begin{array}{l}\text { Auxiliary energy } \\
\text { consumption }\end{array}$ & $5 \% \mathrm{SEC}$ & Electricity cost & Country specific \\
\hline $\begin{array}{l}\text { Efficiency } \\
\text { based on HHV }\end{array}$ & $51.7 \%-$ system & Water cost & $1-2 € / \mathrm{m}^{3}$ \\
\cline { 2 - 4 } & $56.9 \%-$ stack & O\&M & $5 \% \mathrm{CAPEX} /$ year \\
\hline
\end{tabular}

From a cost point of view the economic parameters are summarized in Table 2. Due to the small market reference the specific CAPEX $(€ / \mathrm{kW})$ of the electrolyzer system is hard to determine being extremely variable according to scale, temporal horizon, application, etc. spanning from over $3000 € / \mathrm{kW}$ reported costs for small-scale, R\&D oriented applications up to below $400 € / \mathrm{kW}$ cost projections for large-scale applications by 2030 and onwards ${ }^{10}$. In order to provide a suitable cost analysis a scale-sensitive cost curve (Equation 1) has been implemented $\left(S_{e l}\right.$ between $100 \mathrm{~kW}$ and $\left.1000 \mathrm{~kW}\right)$ calibrated on a base-case scenario $\left(S_{e l, \text { base }}\right.$ $100 \mathrm{~kW}$ with a specific CAPEX of $2000 € / \mathrm{kW}$ ) scaled with a scaling factor (s.f.) of 0.45 , based on elaborations of ${ }^{27}$ and ${ }^{28}$, considering reported costs for similar scales in the timeperiod 2015-2020 which is when the actual procurement of the electrolyzers has taken place.

$$
C_{e l}=C_{\text {base }}\left(\frac{S_{e l, b a s e}}{S_{e l}}\right)^{\text {s.f. }}
$$

The considered CAPEX cost is comprehensive of the whole electrolyzer system, including the balance of plant.

The production scheme is important for the OPEX determination since it is strictly linked to the operating hours and electricity and water consumptions, monetized at their respective prices (retail electricity and water prices, according to the local market conditions and classification of the network connection) ${ }^{29}$. Additional costs for green certificates should be considered, if applicable. A fixed yearly O\&M cost of 5\% of the CAPEX cost has been considered $^{24}$.

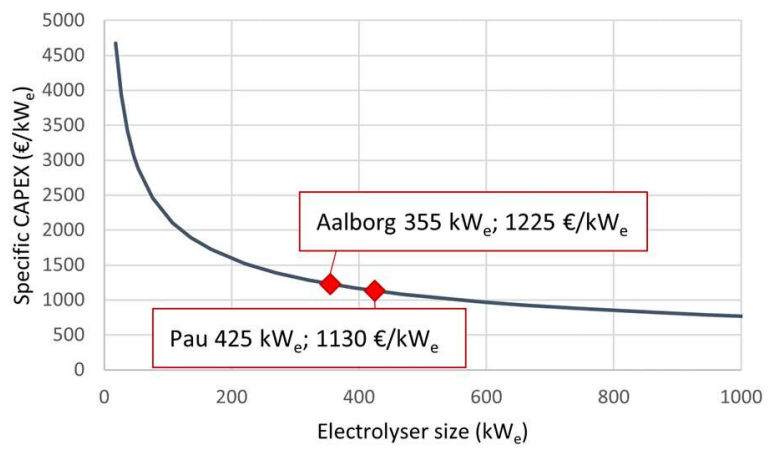

Fig. 2. PEM electrolyzer cost scaling function $\left(€ / \mathrm{kW}_{\mathrm{e}} \mathrm{vs}\right.$. $\mathrm{kW}$ installed). 


\subsection{Hydrogen delivery}

If not produced on-site, hydrogen can be delivered to the HRS externally with different transport methods and distribution schemes. Typically, hydrogen is produced in large-scale centralized plants and then distributed to different end-use consumers through a local distribution network. Since the transport $\&$ distribution cost is added to the production cost the competitiveness of on-site hydrogen production vs. hydrogen supply via delivery is not straightforward and is determined on a case-specific basis ${ }^{18}$.

Typically, for short- to medium-range distances (local distribution within a single country or continent ${ }^{20}, \mathrm{H}_{2}$ is distributed via trucks in compressed gaseous $\left(\mathrm{CGH}_{2}\right)$ form in tube trailers (at 200/350 bar, according to the local regulation in terms of maximum pressure for transport vehicles). Liquid hydrogen trucks $\left(\mathrm{LH}_{2}\right)$ can also be used as transport vector in some specific cases, where the HRS capacity justifies the liquefaction. Thanks to the increased hydrogen mass density in its liquid form $\left(\rho_{\mathrm{LH} 2}=71 \mathrm{~kg} / \mathrm{Nm}^{3}\right) \mathrm{LH}_{2}$ trailers allow to store a much larger hydrogen mass amount in a smaller tank, with respect to gaseous hydrogen $\left(\rho_{\mathrm{CGH} 2}=0.0898\right.$ $\mathrm{kg} / \mathrm{Nm}^{3}$ ), which much require higher pressures ${ }^{30}$. In very few locations in Europe a dedicated hydrogen pipeline is available which can provide a continuous supply of pressurized hydrogen at the point of connection with the final user. In these cases, delivery via pipeline is the most cost-competitive alternative due to the minimal transport $\&$ distribution cost related to the pipeline operation ${ }^{31}$. However, such kind of infrastructure is usually intended as a long-term strategic investment at national level due to the very high upfront CAPEX, which cannot be attributable to a single project since it serves multiple final users.

\subsection{1 $\mathrm{CGH}_{2}$ tube trailers, $\mathrm{LH}_{2}$ trailers and $\mathrm{CGH}_{2}$ pipeline}

Industry-standard compressed gaseous hydrogen tube trailers with a capacity of $350 \mathrm{~kg}$ at 200 bar (around $20 \mathrm{~m}^{3}$ geometrical volume) are used in the delivery-based HRSs (Versailles and - as a backup solution - Pau), following a discrete delivery frequency (usually expressed in deliveries/week). The tube trailer is constituted of a series of compressed vessels which can be left at the HRS, serving as an additional on-site storage volume managed according to the HRS operating scheme. Due to discharging limitations (compressor suction minimum pressure, pressure differences, etc.) not all the stored compressed hydrogen can be used from the tube trailers, a residual pressure of $10 \mathrm{bar}$ (around $17 \mathrm{~kg}$ ) is assumed to be returned to the gas supplier with the trailer.

Regarding cost, the delivered hydrogen is seen from the HRS operator as an OPEX, monetized at its retail price, which is summed to the price related to the transport \& distribution services. Without entering confidential details of the supply contracts which are in place between each HRS operator and gas supplier, a generalized approach has been used in this study setting a retail price of $2.50 € / \mathrm{kg}$ for grey hydrogen and $4 € / \mathrm{kg}$ for blue hydrogen according to relevant cost analyses for the analyzed years ${ }^{10}$. Similarly, the transport \& distribution service price is seen, from the HRS operator point of view, as an OPEX depending on the transport form, distribution scheme, travel distance. For the trailers, the service price is composed of a fixed price, which depends on the number of leased vehicles (as a function of the delivery frequency) multiplied by the monthly trailer lease fee, equal to $2.15 \mathrm{k} € /$ month.vehicle and a variable price in function of the travel distance which includes fuel cost, tolls, special purpose vehicle taxes, etc. which is calculated for a 40-ton vehicle equal to $0.423 € / \mathrm{km}$, based on public transport cost databases ${ }^{32}$. With regards to the pipeline, an additional variable delivery cost related to the energy consumption of the compressors and maintenance of the pipeline is added to the retail cost, according to the transported mass and distance [33]. Furthermore, an additional fixed cost for civil works, estimated around 100,000 $€$, is added to the $\mathrm{CGH}_{2}$ configuration since suitable containment structures should be put in place while operating with a large volume of pressurized hydrogen. 
A summary of the technical and economic parameters of the hydrogen supply by delivery is reported in Table 3.

Table 3. Summary of technical and economic parameters for delivery hydrogen ${ }^{18,32-34}$.

\begin{tabular}{|l|c|c|c|}
\hline & $\mathbf{C G H}_{2}$ trailers & $\mathbf{L H}_{2}$ trailers & $\mathbf{C G H}_{2}$ pipeline \\
\hline Delivered quantity & $\approx 350 \mathrm{~kg} @ 200 \mathrm{bar}$ & $450 \mathrm{~kg}$ & Upon request \\
\hline $\mathrm{H}_{2}$ retail cost & \multicolumn{3}{|c|}{$2.50 € / \mathrm{kg}\left(\right.$ grey H $\left.\mathrm{H}_{2}\right) ; 4.00 € / \mathrm{kg}\left(\right.$ blue $\left.\mathrm{H}_{2}\right)$} \\
\hline Vehicle leasing cost & \multicolumn{2}{|c|}{$2,150 € / \mathrm{month}$. vehicle } & - \\
\hline Transport cost & \multicolumn{2}{|c|}{$0.423 € / \mathrm{km}+20 \%$ profit } & $0.2 € /(\mathrm{kg} .1000 \mathrm{~km})$ \\
\hline Additional civil works & $100,000 €$ & - & - \\
\hline
\end{tabular}

\subsection{Hydrogen compression, storage, dispensing and balance of plant $0,2^{*}$}

Downstream the hydrogen supply section, the HRSs are equipped with compression, storage, and dispensing sections that follow different design concepts and contribute to the final HRS and $\mathrm{H}_{2}$ cost at the dispenser nozzle.

The gas compressor unit (piston, membrane, or ionic technology) increases the pressure from the supply section (at the outlet of the electrolyzer, at the outlet of the pipeline, from a lowpressure buffer storage or directly from the trailer) to the medium- or high-pressure storage unit. The compressor throughput $\left(\mathrm{Nm}^{3} / \mathrm{h}\right)$ is calibrated on the maximum flow rate in case of on-site $\mathrm{H}_{2}$ production by electrolysis or can be reduced in case of delivery $\mathrm{H}_{2}$ considering a lower flow rate throughout the day equal. According to the HRS reliability design requirements, redundancy in the compression section $\left(f_{\text {boost }}\right)$ can be foreseen to avoid the unavailability of the HRS ${ }^{35}$. The compressor electrical consumption $L_{e, \text { compr }}\left(\mathrm{kWh}_{\mathrm{e}} / \mathrm{Nm}^{3}\right)$ is calculated in Equation 2 as a function of the pressure ratio $\beta$, equal to the ratio of the nominal outlet and inlet pressures $\mathrm{p}_{\text {out }} / \mathrm{p}_{\mathrm{in}}$, considering an isentropic multistage compression transformation ${ }^{\dagger}$. The electrical consumption related to the compression is summed to the estimated cooling load. The compressor sizing is determined by multiplying the nominal ${ }^{\sharp}$ electrical consumption $\left(\mathrm{kWh}_{\mathrm{e}} / \mathrm{Nm}^{3}\right)$ by the maximum hydrogen throughput $\left(\mathrm{Nm}^{3} / \mathrm{h}\right)^{31}$.

$$
L_{e, \text { compr }}=c_{p}\left(T_{2}-T_{1}\right)=\frac{c_{p}\left(T_{2}-T_{1}\right)}{\eta_{m} \eta_{e}}=\frac{\sum_{i=1}^{n_{s t}} c_{p}\left(\beta_{s t}^{\frac{k-1}{k}}-1\right)}{\eta_{m} \eta_{e}} \approx \frac{c_{p}\left(\sqrt[n_{s t}]{\beta} \frac{\frac{k-1}{k}}{k}-1\right) n_{s t}}{\eta_{m} \eta_{e}}
$$

Where $c_{p}$ is the isobaric specific heating value $(\mathrm{kWh} / \mathrm{kg} . \mathrm{K})$ of the gas, $\mathrm{T}_{1}$ is the ambient temperature $(\mathrm{K}), \mathrm{T}_{2}$ is the post-compression temperature $(\mathrm{K}), \beta$ is the total pressure ratio and $\beta_{\mathrm{st}}$ is the single-stage pressure ratio, considering $n_{\mathrm{st}}$ the number of stages; $\mathrm{k}$ is the adiabatic coefficient; $\eta_{\mathrm{m}}$ is the mechanical efficiency and $\eta_{\mathrm{e}}$ is the electrical efficiency (a combined mechanical-electrical efficiency of $60 \%$ has been considered). The energy consumption is assumed to be equally spread between the compression stages as a simplifying assumption. The storage section comprises one or more storage units, type III or type IV pressure vessels or tanks according to the nominal pressure level. The storage can be split into different pressure levels (multi-pressure HRS) or grouped at a single pressure level, according to the design of the HRS. The storage management depends on the number of controllable valves and interconnections between compression, storage, and dispensing units. The storage capacity $(\mathrm{kg})$ is usually preliminarily sized according to the daily capacity of the HRS (kg/day). Typically, the storage is sized for around 1 day of nominal capacity, although such

\footnotetext{
$\dagger$ Considering an isentropic transformation is a conservative assumption since the compressors are usually multistage \& inter-refrigerated, therefore an isothermal transformation with $\mathrm{T}_{2}$ equal to $\mathrm{T}_{1}$ (ambient temperature) would be more representative of the actual compression.

$\$$ In addition, the use of the nominal $\beta$ is also a conservative assumption since given the dynamic charge/discharge dynamics of the storage units the compression will likely occur at a lower $\beta$ respect to the nominal.
} 
parameter can range between 0.5-5 days of nominal capacity in relation to the $\mathrm{H}_{2}$ refuelling demand scheme and sustain possible HRS unavailability periods ${ }^{36}$.

The dispensing unit controls the pressure-driven refueling process towards the vehicle via a pressure reduction valve with a control system that follows the refueling protocol subject to the SAE J2601 standard, which determines the Average Pressure Ramp Rate (APRR) towards the receiving vehicle tanks. Due to the characteristics of heavy-duty mobility refueling (target pressure of 350 bar, longer refueling times, higher refueled amounts, etc.) pre-cooling is usually not needed. As a generalization, dispensers can be categorized by refueling speed capacity - slow filling ( $>15$ minutes refueling), fast filling $(<15$ minutes refueling) - or by pressure level - single pressure (350 bar or 700 bar) and dual pressure dispensers (both $350 / 700$ bar refueling pressure) ${ }^{15}$.

In addition, the HRS is equipped with general purpose plant auxiliary units (ventilation systems, safety systems, lighting, pipeline, integration, etc.), whose installed power is considered equal to $5 \%$ of the total installed power $\mathrm{P}_{\text {inst }}$ (sum of electrolyzer, compressors, coolers, etc.) in case of on-site producing HRSs and at least $20 \mathrm{~kW}_{\mathrm{e}}$ for delivery HRSs. As a conservative assumption, the auxiliary systems are considered to operate $24 / 24 \mathrm{~h}$. Civil and electrical works depend on the compressed hydrogen amount and pressure levels and on the installed electrical power, respectively and are regulated by national standards.

In terms of cost, the compression, storage, dispensing and balance of plant units are all determined via cost functions for CAPEX and OPEX. The compression CAPEX is determined based on the installed electrical power $(\mathrm{kW})$ and the redundancy factor $\mathrm{f}_{\text {boost }}(\%)$ - including inter-cooling system; the OPEX depends on the electrical consumption monetized at the electricity retail price $c_{\text {el }}(€ / \mathrm{kWh})$, other than the O\&M cost ${ }^{15,31,37}$. The $\mathrm{CGH}_{2}$ storage CAPEX is calculated as a function of hydrogen capacity $(\mathrm{kg})$ and pressure level (bar), taking into account the additional cost of management valves for larger quantities ${ }^{15}$; the OPEX is only composed of O\&M since the storage unit is passive in terms of energy consumption. The dispensing unit CAPEX is determined according to the hydrogen refueling capacity ( $\mathrm{kg} /$ day) differentiated based on the categorization of the dispensing unit (slow filling, fast filling, single/dual pressure) factor $\mathrm{f}_{\text {disp }}$ which varies between 1-1.5; the OPEX is only O\&M since the dispensing system is passive as well (no pre-cooling considered) [15]. Finally, the balance of plant presents some additional CAPEX and OPEX costs, based on the installed power and the electricity consumption, monetized at the electricity retail price $c_{\mathrm{el}}$ $(€ / \mathrm{kWh})^{18}$.

The summary of the technical and economic parameters of the compression, storage, dispensing and balance of plant sections of the HRS are reported in Table 4.

Table 3. Summary of technical and economic parameters for the compression, storage, dispensing and balance of plant sections of the HRS ${ }^{31},{ }^{15,38},[14,18,36]$.

\begin{tabular}{|c|c|c|c|c|c|}
\hline & & Compressor & Storage & Dispenser & $\begin{array}{l}\text { Balance of } \\
\text { Plant }\end{array}$ \\
\hline \multicolumn{6}{|c|}{ Technical parameters } \\
\hline \multicolumn{2}{|c|}{ Sizing criteria } & $\begin{array}{l}\text { Qmax }_{\text {max }} \text { production }\left(\mathrm{Nm}^{3} / \mathrm{h}\right) \\
\mathrm{Q}_{\text {avg }} \text { delivery }\left(\mathrm{Nm}^{3} / \mathrm{h}\right)\end{array}$ & $\begin{array}{c}\text { Days of nominal } \\
\text { capacity }(\mathrm{kg})\end{array}$ & $\begin{array}{c}\text { Nominal capacity } \\
(\mathrm{kg} / \text { day })\end{array}$ & $\begin{array}{c}5 \% \mathrm{P}_{\text {inst }} \text { (onsite) } \\
\geq 20 \mathrm{~kW}_{\mathrm{e}} \text { (delivery) }\end{array}$ \\
\hline \multicolumn{2}{|c|}{$\begin{array}{l}\text { Energy } \\
\text { consumption }\end{array}$} & Eq. $2+20 \%$ cooling & - & - & $24 / 24 \mathrm{~h} ; \eta_{\mathrm{e}}=0.97 \%$ \\
\hline \multicolumn{6}{|c|}{ Economic parameters } \\
\hline \multicolumn{2}{|c|}{ CAPEX } & $15,000 x^{-0.4} f_{\text {boost }}^{*} \in / \mathrm{kW}_{\mathrm{e}}$ & $350-1000 € / \mathrm{kg}_{\mathrm{H} 2}{ }^{* *}$ & $\begin{array}{c}f_{\text {disp }}^{* * *} 350 \\
€ /(\mathrm{kg} / \text { day }) \\
\end{array}$ & $200 € / \mathrm{kW}_{\mathrm{e}}$ \\
\hline \multirow{2}{*}{ OPEX } & Energy & Eq. $2 \times c_{\mathrm{el}}$ & - & - & $\mathrm{P}_{\text {aux }} \mathrm{X} \mathrm{c}_{\mathrm{el}}$ \\
\hline & $\mathrm{O} \& \mathrm{M}$ & 4\% $\%_{\text {CAPEX }} /$ year & $2 \%_{\text {CAPEX }} /$ year & $2 \%_{\text {CAPEX }} /$ year & $10 \%_{\text {CAPEX }} /$ year \\
\hline
\end{tabular}

" compressor boost coefficient; $\mathrm{f}_{\text {boost }} \geq 1$ 
${ }_{* * * *}^{* *}$ calibrated based on nominal pressure, stored capacity and management valves units

${ }^{* * *}$ depending on dispenser type \& pressure; $1<\mathrm{f}_{\text {disp }}<1.5$

\section{Results and Discussion}

The cost model has been run for the five HRS sites, considering a classical project finance approach with a standard time horizon of 15 years and an interest rate $i$ equal to 7\%. The results of the cost model in terms of HRS cost (M€ and breakdown between CAPEX and OPEX contributions) and $\mathrm{LCOH}$ at the nozzle $(€ / \mathrm{kg}$ and breakdown between CAPEX and OPEX contributions) are reported in this section, together with some comparative parameters to contextualize the differences in the cost model results.

Despite the differences between each HRS, recurrent cost patterns can be identified between the delivery HRSs (London, Rhoon and Versailles) and on-site HRSs (Pau and Aalborg). In particular, the delivery-based HRSs are predominantly OPEX-driven (up to $85-90 \%$ of the annualized total cost), where the retail hydrogen price is the most significant parameter for the definition of the $\mathrm{LCOH}$. In addition, the delivery configuration with on-site storage of the tube trailer helps to smoothen the compression load since the compressor is operated with lower $\beta$ ratios and over longer time periods, resulting in a slight cost reduction in the compression/storage sections. On the other hand, on-site production HRSs present a higher CAPEX contribution (around $25-30 \%$ of the annualized), due to the high electrolyzer CAPEX $\left(>1000 € / \mathrm{kW}_{\mathrm{e}}\right)$ cost, although the OPEX still dominates the $\mathrm{LCOH}$, especially in terms of electricity price, which is an important parameter since the electrolyzer presents a very high specific electricity consumption $\left(>50 \mathrm{kWh}_{\mathrm{e}} / \mathrm{kg}_{\mathrm{H} 2}\right)$. For both HRSs, the compression and storage sections represent a relevant but not prevalent contribution for the $\mathrm{LCOH}$ (around $1-3 € / \mathrm{kg}$ ) according to the HRS design specifications and different design concepts in terms of required reliability, redundancy and single/multi-pressure approach (e.g. Pau presents a much more complex compression/storage section with multi-pressure storage units and parallel compressors respect to London which only presents a single on-site storage unit and the compressor is integrated within the $\mathrm{LH}_{2}$ trailer). The dispensing system does not usually represent a significant portion of the total cost, although the dispensing can become more relevant in HRS with many dispensing points (e.g., Pau) or with fast fuelling or dual-pressure dispensers (e.g. Versailles) and although the dispensing system design is directly linked to the vehicle fleet refueling logistics, which can play a key role in the operation of the HRS. Figure 3 and Figure 4 illustrate an example of an HRS cost breakdown for a delivery HRS and an on-site producing HRS.

\section{Annualized cost \& LCOH composition}

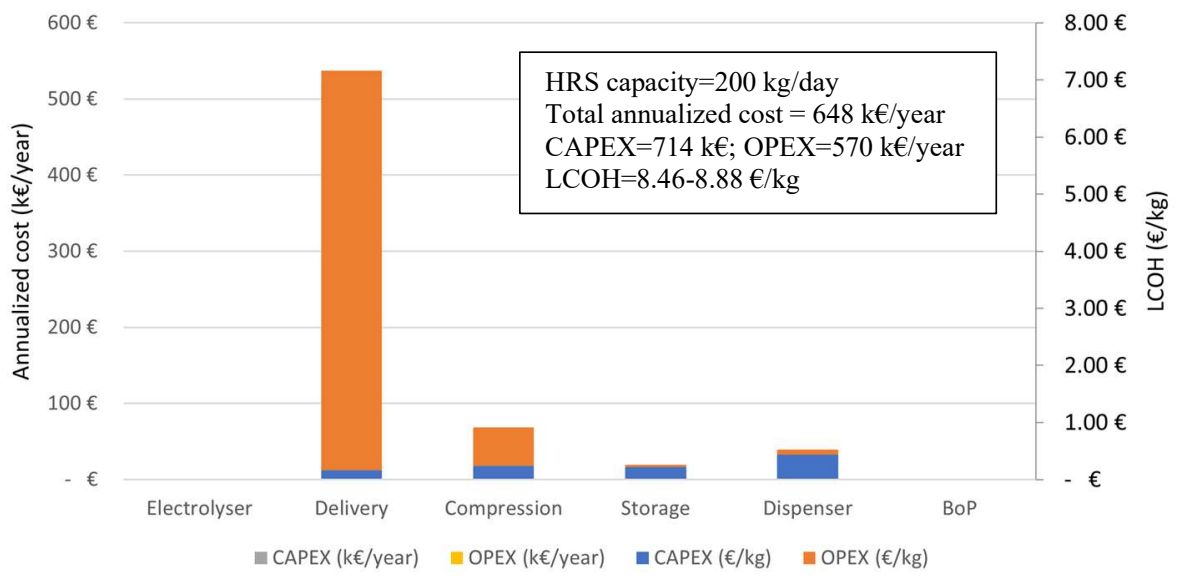


Fig. 3. Example of delivery-based HRS (Versailles) in terms of annualized total cost ( $€$ /year) and $\mathrm{LCOH}(€ / \mathrm{kg})$.

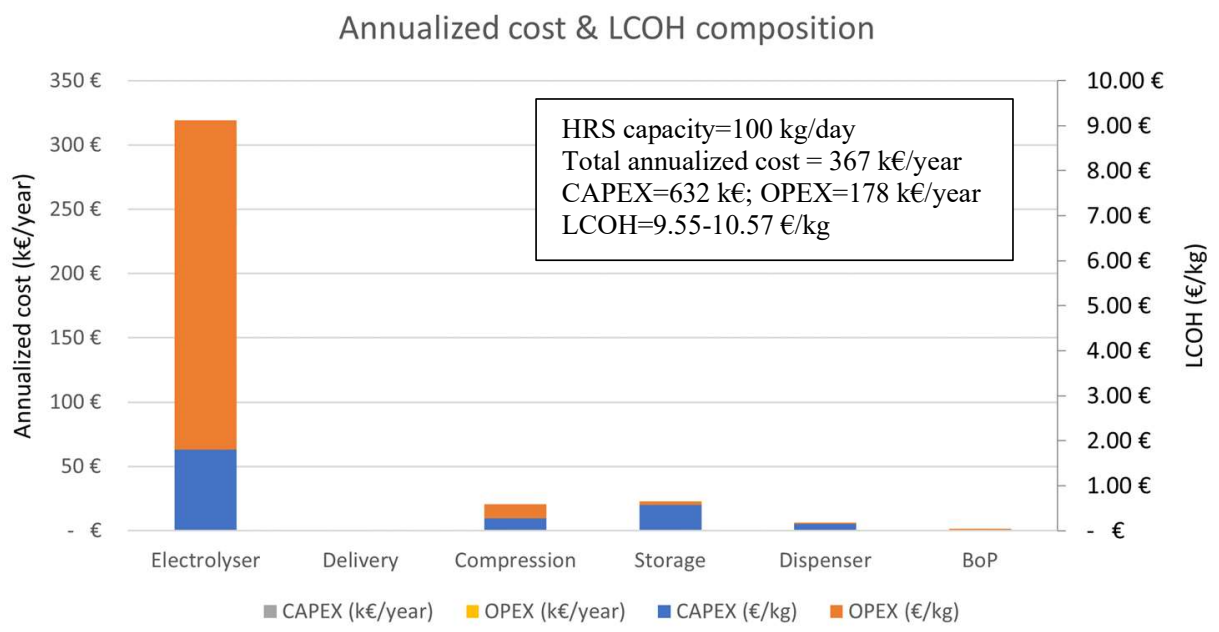

Fig. 4. Example of on-site production-based HRS (Aalborg) in terms of annualized total cost ( $€$ /year) and $\mathrm{LCOH}(€ / \mathrm{kg})$.

Overall, similar results in terms of $\mathrm{LCOH}$ are be found for the different configurations (between 8-12 €/ kg). For the considered HRS capacities (100 kg/day up to $400 \mathrm{~kg} /$ day), delivery HRS schemes (LCOH between $8-9 € / \mathrm{kg}$ for London and Versailles) are still more convenient than on-site producing HRSs (LCOH around 11-12 €/ $/ \mathrm{kg}$ ); the Rhoon HRS presents a particularly competitive $\mathrm{LCOH}(5.75-6.15 € / \mathrm{kg})$ considering the pipeline delivery whose CAPEX is not accounted for in the HRS cost model and due to the very low service cost, even for large amounts of $\mathrm{H}_{2}$ transported over long distances. The financial cost (considering the assumed scenario of 15 years and 7\% interest rate) has an impact between $5-10 \%$ of the final cost, which is relevant especially for CAPEX-intensive HRS schemes.

The cost model results for all the HRSs are summarized in Table 4.

Table 4. Summary of cost model results for all HRSs (delivery $\&$ on-site) in terms of CAPEX/OPEX $\& \mathrm{LCOH}$ contributions.

\begin{tabular}{|l|l|l|l|l|l|l|}
\hline & $\begin{array}{l}\text { CAPEX } \\
(\mathrm{k} €)\end{array}$ & $\begin{array}{l}\text { OPEX } \\
(\mathrm{k} € / \text { year })\end{array}$ & $\begin{array}{l}\text { LCOH } \\
(€ / \mathrm{kg})\end{array}$ & $\begin{array}{l}\text { LCOH } \\
(€ / \mathrm{kg})\end{array}$ & $\begin{array}{l}\text { LCOHEX } \\
(€ / \mathrm{kg})\end{array}$ & $\begin{array}{l}\mathrm{C}_{\text {HRS,CAPEX }} \\
(\mathrm{k} /(\mathrm{kg} / \text { day }))\end{array}$ \\
\hline London & 414 & 469 & 8.81 & 0.78 & 8.03 & 4.26 \\
\hline Rhoon & 701 & 375 & 6.19 & 1.05 & 5.14 & 5.77 \\
\hline Versailles & 714 & 570 & $8.88 €$ & 1.07 & 7.81 & 5.88 \\
\hline Pau & 2,004 & 544 & 12.02 & 3.46 & 8.56 & 18.97 \\
\hline Aalborg & 632 & 268 & 10.57 & 2.84 & 7.73 & 10.37 \\
\hline
\end{tabular}

Analyzing the aggregated specific CAPEX cost based on the HRS capacity ( $\mathrm{C}_{\text {HRS,CAPEX}}$ ), it can be noticed that while delivery based HRSs span between $4-6 \mathrm{k} € /(\mathrm{kg} /$ day $)$, which is quite in line with comparable literature ${ }^{12},{ }^{13}$ instead, for the on-site producing HRS schemes, such parameter can see a two/three-fold increase due to the previously discussed higher upfront CAPEX contribution, related to the electrolyzer and the less advantageous design specifications of the rest of the systems. 


\section{Conclusions}

A detailed component-oriented cost model has been applied to five different real HRS configurations to assess the HRS cost and the LCOH at the dispenser nozzle. The disaggregated approach to the cost model (CAPEX and OPEX for each component/subsystem) allows to correctly compose the final HRS cost and LCOH with sufficient detail, allowing to identify the most critical cost parameters for different HRS design concepts (delivery-based and on-site producing).

The results confirm that the $\mathrm{H}_{2}$ price at the nozzle of small scale HRSs can range between 6$12 € / \mathrm{kg}$, which is in line with the literature, standard market prices for the analyzed HRS capacity range and with the 3 Emotion project targets. The LCOH is mainly composed of the cost of $\mathrm{H}_{2}$ itself (either delivered or produced on-site - which accounts for at least $5 € / \mathrm{kg}$ ), to which the compressor, storage and dispensing costs are added to reach the final cost at the dispenser nozzle at 350 bar. For the considered HRS capacity ( $100 \mathrm{~kg} / \mathrm{day}$ to $400 \mathrm{~kg} / \mathrm{day})$, it is still more convenient to deliver $\mathrm{H}_{2}$ to the HRS (LCOH 8-9 $€ / \mathrm{kg}$ for London and Versailles) than to produce it on-site ( $\mathrm{LCOH}$ approximately $11-12 € / \mathrm{kg}$ ); the Rhoon HRS has a particularly competitive $\mathrm{LCOH}(5.75-6.15 € / \mathrm{kg})$, thanks to the low cost pipeline delivery although its CAPEX is not considered within the HRS cost model, since it is a larger scale infrastructure which serves multiple users.

Delivery-based HRSs (London, Rhoon, Versailles) are typically OPEX-dominated ( $>85 \%$ of the annualized cost), for which the $\mathrm{H}_{2}$ retail price represents the main cost contribution, together with the transport service price. Since the main cost contributions are externalized, it is of foremost importance to establish convenient long-term contract prices (for both gas retail and transport) with the gas supplier to ensure competitive cost reduction from the HRS operator point of view.

On-site producing HRSs (Pau, Aalborg) present a stronger contribution of the CAPEX (25$30 \%$ of the annualized cost), although the $\mathrm{LCOH}$ in the long term is still driven by the OPEX (in this case, especially by electricity price). Producing hydrogen on-site is still not convenient for the analyzed HRS sizes (up to $400 \mathrm{~kg}$ /day) since significant scale economies cannot be obtained in terms of electrolyzer cost. Also, the rest of the compressor and storage systems have to be sized according to the electrolyzer maximum production capacity (while for delivery schemes, the trailers can be discharged more gradually), and the compression ratios are generally higher with respect to delivery-based HRS schemes (starting from 30 bar respect to 200 bar in case of delivery $\mathrm{H}_{2}$ ).

The cost-competitiveness of delivery-based HRS schemes with respect to on-site production HRS schemes could be inverted in the future when with larger-scale HRSs ( $>400 \mathrm{~kg} /$ day), greater economies of scale can be untapped for electrolyzer systems, and the cost of distribution \& transport could surpass the cost to produce the hydrogen on-site with a decentralized approach.

Although defining an aggregate value to determine the HRS CAPEX in function of the capacity is desirable in order to assess the cost of a HRS quickly, this approach is too general. In fact, the specific HRS CAPEX cost ( $\mathrm{C}_{\mathrm{HRS}, \mathrm{CAPEX}}$ ) depends not only on the HRS capacity but also on the HRS type and design concept. Much higher values (two- to three-fold) are found for on-site producing HRSs, due to the increased CAPEX with respect to delivery HRSs. This confirms that it is not suitable to assess the cost of an HRS with respect to its nominal capacity with a one-size-fits-all aggregate cost curve and that a more detailed, component-oriented analysis is necessary.

As a future perspective of this work, the cost model should be integrated with operational aspects related to the HRS components and the vehicle fleet operation and logistics to provide a fully integrated design \& operational based cost model of the HRS to assess the technical and economic implications not only at design level but also in real-life operation. 


\section{References}

1. Chatzimarkakis, J., Levoyannis, C., van Wijk, A. \& Wouters, F. Hydrogen Act Towards the creation of the European Hydrogen Economy. (2021).

2. Li, Y., Kool, C. \& Engelen, P. J. Analyzing the business case for hydrogen-fuel infrastructure investments with endogenous demand in the Netherlands: A real options approach. Sustainability 12, (2020).

3. Hydrogen Council. Hydrogen scaling up. A sustainable pathway for the global energy transition. www.hydrogencouncil.com. (2017).

4. FCH JU. Hydrogen roadmap Europe. A sustainable pathway for the European energy transition. (2019) doi:10.2843/249013.

5. Hydrogen Mobility Europe. Emerging Conclusions. (2020).

6. Hecht, E. S. \& Pratt, J. Comparison of conventional vs. modular hydrogen refueling stations, and on-site production vs. delivery. www.sandia.gov.

7. Jovan, D. J. \& Dolanc, G. Can Green Hydrogen Production Be Economically Viable under Current Market Conditions. Energies 13, 6599 (2020).

8. China Deloitte. Fueling the Future of Mobility Hydrogen and fuel cell solutions for transportation. Financ. Advis 1 (2020).

9. Hecht, E. S. \& Pratt, J. Comparison of conventional vs. modular hydrogen refueling stations, and on-site production vs. delivery. www.sandia.gov (2017).

10. IRENA. Green Hydrogen Cost Reduction; Scaling up Electrolysers to meet the 1.5 C Climate Goal. www.irena.org/publications (2020).

11. Melaina, M. \& Penev, M. Hydrogen Station Cost Estimates. (2013).

12. Bush, B. \& Melaina, M. National FCEV and Hydrogen Fueling Station Scenarios. in (2016).

13. Murthy Konda, N. V. S. N., Shah, N. \& Brandon, N. P. Optimal transition towards a large-scale hydrogen infrastructure for the transport sector: The case for the Netherlands. International Journal of Hydrogen Energy 36, 4619-4635 (2011).

14. Viktorsson, L., Heinonen, J. T., Skulason, J. B. \& Unnthorsson, R. A step towards the hydrogen economy - A life cycle cost analysis of a hydrogen refueling station. Energies 10, (2017).

15. Weinert, J. X. \& Lipman, T. An assessment of the near-term costs of hydrogen refueling stations and station components. Inst Transp Stud (2006).

16. Fragiacomo, P. \& Genovese, M. Technical-economic analysis of a hydrogen production facility for power-to-gas and hydrogen mobility under different renewable sources in Southern Italy. Energy Conversion and Management 223, (2020). 
17. Minutillo, M., Perna, A., Forcina, A., di Micco, S. \& Jannelli, E. Analyzing the levelized cost of hydrogen in refueling stations with on-site hydrogen production via water electrolysis in the Italian scenario. International Journal of Hydrogen Energy 46, 1366713677 (2021).

18. Monforti Ferrario, A., Rajabi Hamedani, S., del Zotto, L., Santori Simone, G. \& Bocci, E. Techno-economic analysis of in-situ production by electrolysis, biomass gasification and delivery systems for Hydrogen Refuelling Stations: Rome case study. in Energy Procedia vol. 148 82-89 (Elsevier Ltd, 2018).

19. 3Emotion. 3Emotion | Environmentally friendly, efficient, electric motion (2021).

20. Hydrogen Council. Hydrogen Insights A perspective on hydrogen investment, market development and cost competitiveness. www.hydrogencouncil.com. (2021).

21. Micena, R. P., Llerena-Pizarro, O. R., de Souza, T. M. \& Silveira, J. L. Solar-powered Hydrogen Refueling Stations: A techno-economic analysis. International Journal of Hydrogen Energy (2019) doi:10.1016/j.ijhydene.2019.11.092.

22. Elgowainy, A. Economic and Environmental Perspectives of Hydrogen Infrastructure Deployment Options. (2019).

23. Bertuccioli L et al. Study on development of water electrolysis in the EU. www.e4tech.com (2014).

24. Gallardo, F. I. et al. A Techno-Economic Analysis of solar hydrogen production by electrolysis in the north of Chile and the case of exportation from Atacama Desert to Japan. International Journal of Hydrogen Energy 46, 13709-13728 (2021).

25. Carmo, M., Fritz, D. L., Mergel, J. \& Stolten, D. A comprehensive review on PEM water electrolysis. International Journal of Hydrogen Energy vol. 38 4901-4934 (2013).

26. SAE. J2719_202003. Hydrogen Fuel Quality for Fuel Cell Vehicles . https://www.sae.org/standards/content/j2719_202003/ (2020).

27. Eypasch, M. et al. Model-based techno-economic evaluation of an electricity storage system based on Liquid Organic Hydrogen Carriers. Applied Energy 185, 320-330 (2017).

28. Felgenhauer, M. \& Hamacher, T. State-of-the-art of commercial electrolyzers and on-site hydrogen generation for logistic vehicles in South Carolina. International Journal of Hydrogen Energy 40, 20842090 (2015).

29. Statista. Statista, Energy Indicators, Global Energy Prices - statistics \& facts. https://www.statista.com/topics/1323/energy-prices/ (2021).

30. Reuß, M. et al. Seasonal storage and alternative carriers: A flexible hydrogen supply chain model. Applied Energy 200, 290-302 (2017). 
31. Reuß, M., Grube, T., Robinius, M. \& Stolten, D. A hydrogen supply chain with spatial resolution: Comparative analysis of infrastructure technologies in Germany. Applied Energy 247, 438-453 (2019).

32. Ministero dei trasporti. Costo chilometrico medio relativo al consumo di gasolio delle imprese di autotrasporto per conto terzi. (2009).

33. ENTSOG, GIE \& Hydrogen Europe. How to transport and store hydrogen-facts and figures. (2021).

34. Yang, C. \& Ogden, J. Determining the lowest-cost hydrogen delivery mode. International Journal of Hydrogen Energy 32, 268-286 (2007).

35. Simonnet, A. UC Davis Working Papers Title Technical Options For Distributed Hydrogen Refueling Stations in a Market Driven Situation Permalink https://escholarship.org/uc/item/3m3308s2 Publication Date. https://escholarship.org/uc/item/3m3308s2 (2005).

36. Prince-Richard, S., Whale, M. \& Djilali, N. A techno-economic analysis of decentralized electrolytic hydrogen production for fuel cell vehicles. International Journal of Hydrogen Energy 30, 11591179 (2005).

37. Reddi, K., Elgowainy, A., Rustagi, N. \& Gupta, E. Impact of hydrogen SAE J2601 fueling methods on fueling time of light-duty fuel cell electric vehicles. International Journal of Hydrogen Energy 42, 16675-16685 (2017).

38. Reddi, K., Elgowainy, A., Rustagi, N. \& Gupta, E. Impact of hydrogen refueling configurations and market parameters on the refueling cost of hydrogen. International Journal of Hydrogen Energy 42, 21855-21865 (2017). 